\title{
Research on the Development and Enhancement of Architectural Design Industry Human Resources Management System based on Comprehensive Performance Evaluation
}

\author{
Zhang Juan ${ }^{1}$ \\ ${ }^{1}$ Xi'an International University, \\ Xi'an 710077,China
}

\begin{abstract}
In this paper, we research on the development and enhancement of architectural design industry human resources management system based on comprehensive performance evaluation. With the rapid development of our country's economy, construction industry is facing huge development space and opportunities, enterprise the key to win the initiative to develop. Human resources are the first resource of the knowledge economy era which is a construction enterprise survival and development of the necessary resources. Our research will help the managers and business institutes to modify the performance evaluation standard to optimize their enterprise.
\end{abstract}

Keywords: Human Resources; Comprehensive Performance; Evaluation and Enhancement.

\section{Introduction}

Human resource is not only the necessary condition to the development of the construction industry, is also the precondition of construction on growing factors, our country with the development trend of the era of knowledge economy, globalization synchronous represented by intelligent human capital, science and technology as the core system, construct new productivity represented by high technology development of core technical knowledge era, in the face of foreign capital and private enterprise human resource competition, construction enterprises how to revitalize the stock of internal human resources has become the problem must seriously face at present. With the rapid development of our country's economy, construction industry is facing huge development space and opportunities, enterprise the key to win the initiative to develop, is the enterprise human resources, who can effectively manage and develop human resources, who can gain more competitive advantage. Current our country construction enterprise the overall quality of human resources is low, single incentive mechanism, lack of training and so on, restricts the benign development of construction enterprises, speed up the development of human resources and training, strengthen the construction of enterprise human resources quality and improve human resources management strategy which has become a problem to be solved. Human resources are the first resource of the knowledge economy era which is a construction enterprise survival and development of the necessary resources [1].

The existing problems in construction enterprises in human resources management could be summarized as the follows. (1) Exploitation of the lack of human resources management. Human resources and building enterprises of other resources is a systematic engineering. Is at present a lot of construction enterprise managers in the HR system for management and no in-depth research, lack of development efforts, and its human resources management concept is still in a primary stage, not from the eyes of the global problems, cannot system in the allocation of human resources in enterprises, lead to improper use or cause waste of human resources. In building enterprise personnel fluidity big and other factors have also led to construction enterprise of talent and light weight experience required for potential, 
insufficient attention to personnel training, ignoring the real training of talents, lead to the low level of human resource team as a whole, not to do a good job of infrastructure assurance for the enterprise. (2) Its quality is not high and the building enterprise leaders alternate too fast. Because of the old building enterprise leaders on the management of human resources is not high, lead to business leaders in the understanding of the professional knowledge of human resource management is not deep, it also limits the construction enterprises in the management of the construction personnel can't have a very good leading and management effect. Individual idea advanced construction enterprise, although has already started to learn some advanced knowledge of human resource management, but since there is no from the deep culture of our nation, also can't really blend in human resources management into their own enterprise management. (3) Construction enterprise human resource management system is not sound. Market of huge human resources allocation of power can't play a proper role in the construction enterprises [2]. Combined with construction work personnel fluidity big, quality is uneven, enterprises in the absence of establishing and perfecting the incentive mechanism, the construction of enterprise human resources management structure and management mechanism cannot get perfect formulation and implementation.

The human resource management mode of construction projects and project organization structure in the form of association is very close, if according to the function type organization structure form, the division of the work of project members' coordination is the main content of project human resource management. Project if according to the type of project organization structure building and in addition to the above content, project personnel obtain working content will be included in the human resources management work content. For smaller, shorter cycle of construction projects, the project team development can hardly be as the main content of its human resources management work and for the cycle time is longer, the larger projects and the adjustment and development of the project team is must focus on the job [3].

In this paper, we research on the development and enhancement of architectural design industry human resources management system based on comprehensive performance evaluation. Human resource management can't be limited to simply a department and it should run through the whole enterprise management. The implementation of the strategy of enterprises should be supported by human resources strategy. Only a detailed and system by the human resources project of members to participate in planning is the sole basis for successful human resources management. Thus, to build a good enterprise culture atmosphere, let employees belonging to the enterprise to improve the employee loyalty. In the following, more detailed discussion will be discussed and researched.

\section{The Principles of Our Research}

The Basic Concept of Human Resources Management. Human resource management is the basic management of a new and important field, far beyond the confines of the traditional personnel management. We know that perfect human resource management system is a powerful guarantee for human resource management. Construction engineering projects, the power and responsibility distribution is reasonable, will directly affect the project human resource management. Generally, whatever the project, in the management process will be a certain degree is the unreasonable phenomenon of power and responsibility assignment, once the power is too concentrated in the process of management, will be serious results in the decrease of effect of human resources management, the human resources management cannot play a real role.

Varying levels of project for the needs of the organization is very different, relatively correct 
organizational structure can to a certain extent, improve the level of the project of human resource management, on the contrary, the relatively backward organization, will inevitably lead to quickly reduce the management level. Construction project involves all aspects of personnel management, from the personnel selection, to the knowledge staff training and assessment, etc., all belong to management. And personnel management system conformed to certain rules which will also directly affect the human resource management level. Of course, should also be in the process of continuously improve the management mechanism, only in this way can effectively promote the improvement of human resource management. The influence factors of human resource management system which will be directly related to the improvement of the management level or not. Therefore, should be focused in the management process, and at the same time of ensuring effective management, to improve their management level. In the current construction industry in our country, the human resources management also has some of the more typical problems, greatly influenced the performance of the whole project level, thus to optimize the project human resource management system, reasonable configuration and use of human resources in building project, and the corresponding incentive and training system to improve in order to put the motility maximum.

\section{The Comprehensive Performance}

Evaluation. Performance appraisal in the process of building enterprise strategic target decomposition to perform is to all departments and positions and objective evaluation of the content of the strategic target decomposition to perform. This work need to have perfect performance appraisal system, and an objective and fair, fair performance appraisal method and content. Enterprise performance evaluation standard is also different. This requires enterprises in the strategic target decomposition in the process of the scientific performance evaluation and assessment according to the work of different departments, post content determination of way and the examination content. A simple performance appraisal does not arouse the enthusiasm of employees, standard execution. In the strategic target decomposition, with the complex application of performance evaluation and enterprise also merit pay this management mode should be introduced, that is, to promote the enthusiasm of staff strategy, the decomposition of the enterprise which will promote enterprise strategic management work.

For construction enterprises, project management in construction enterprise occupies an extremely important status in the entire enterprise management, it is the microcosmic basis of enterprise which is the basis of enterprise management, is the main part of the enterprise management which is the concentrated reflection of the enterprise comprehensive strength and level. Engineering projects are the sites of production factors and reality combine and comprehensively improve the comprehensive benefit of engineering, depend on scientific and effective management of engineering. In project management as the center, improve project operation quality and management level, is the eternal theme in building enterprise survival and development shown in the following. 


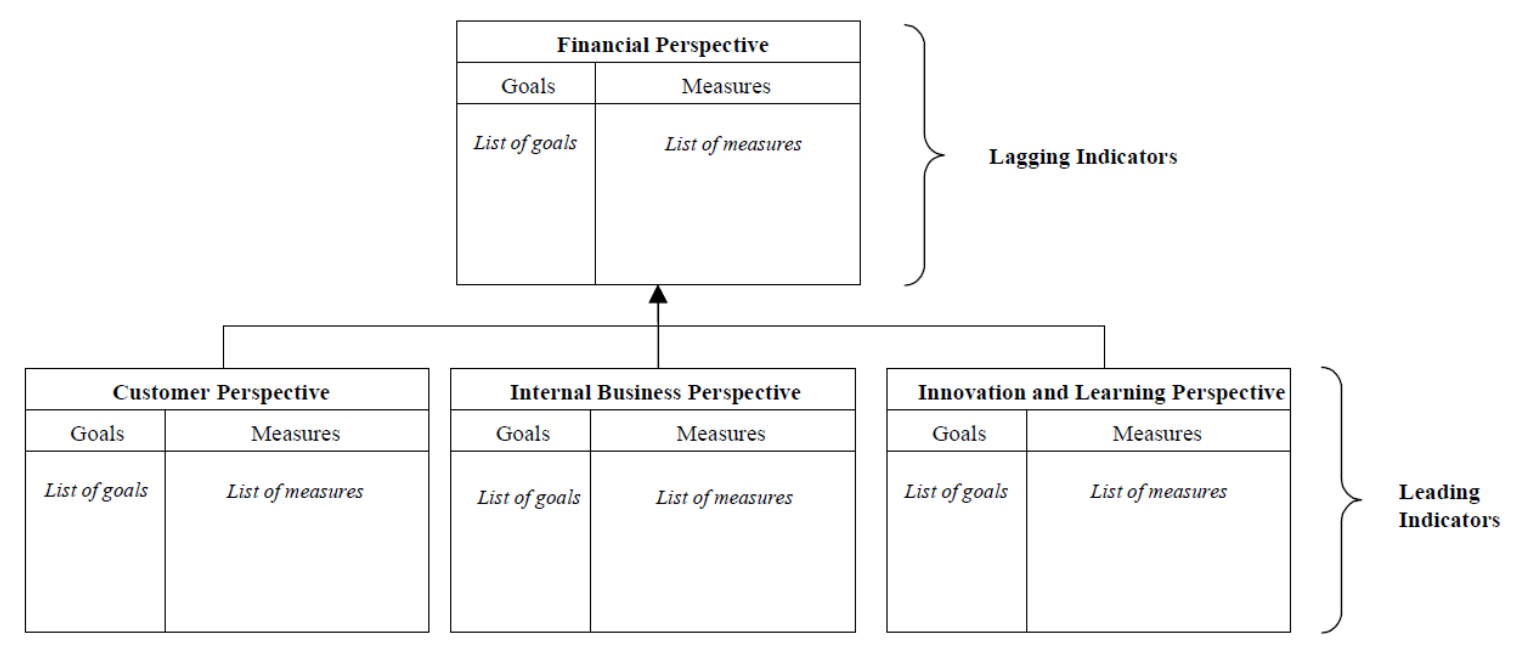

Figure 1. The General Struccture and Flowchart of the Comprehensive Performance Evaluation

Task performance will be because of the time, space, factors related to environmental changes, thus presents the obvious diversity, multidimensionality and dynamic, it also determines the overall evaluation of performance must be a multi-angle, multidimensional and multi-level. Key performance indicators, it is through the organization of internal processes the input, output, the key parameters setting, sampling, calculation and analysis, a target type quantitative management measure of process performance index, is a key success factors in the process of enterprise operation of refining and summarized. The core elements could be separated into the following parts. (1) Integration and analysis of the internal process. Based on the internal process integration design of key performance indicators will make employees know their own indicators and responsibility is to serve for which a process, to the operation of other departments and even the whole of the enterprise will produce what kind of impact. Therefore, must carry on the refinement is the premise of key performance indicators for internal process integration and analysis. (2) The general extraction of departmental key performance indicators. Decomposition at the same time should pay attention to according to the function of each department to decompose indicators to adjust, and both its correlation with the department in charge of the superior indicators. (3) To determine the general enterprise strategic target. Overall strategic goals of the enterprise in accordance with the internal some of the main business process is decomposed into several major support to strike the targets. (4) Clear enterprise's overall strategic objectives. According to enterprise strategic direction, from increase profits, improve profitability, improve the quality of staff Angle respectively determine the strategic focus of the enterprise, and using the design method of key performance indicators are analyzed, and clear the enterprise overall strategic target. (5) Form a key performance index system. According to department key performance indicators, business processes and the job description of each position to decompose should be the department goal.

The Architectural Design Industry Human Resources Management. Performance evaluation is not possible completely fair, also cannot fully take into account the interests of all aspects, but should fully recognize the leading role of performance evaluation system, outstanding work, is crucial to project overall performance, to bring project performance obviously increase the sufficient jobs and personal motivation, the wage distribution combined with the results of staff appraisal, change the situation of gap is too small, 
difference, clear rewards and punishment system, increase transparency, fully embodies the principle of democratic equality, make the staff to the project produces trust, arouse the enthusiasm of the employees' work. Due to the merger and reorganization of the construction industry and public profits, building project competition focus has gradually shift from money to quality and innovation, in addition to the change require employees have prominent performance, outstanding achievement, also require employees to show more creative and innovative.

Construction project managers need to realize that creative senior intellectuals is to create the talent project profit, diligent work of the same project line construction personnel, the foundation for steady progress. Should the employees as the most precious resource and project both for received the highly educated talents of higher education, or from the construction of a gleam of exercise grew up self-study type talented person, should try to satisfy their needs of different levels, helping them achieve self-perfection. At the same time, we should regularly communicate with employees, reduce the distance relationship and create harmonious and relaxed working atmosphere for employees.

\section{Conclusion}

In this paper, we research on the development and enhancement of architectural design industry human resources management system based on comprehensive performance evaluation. With the development of our country's economy, construction companies as a pillar industry in China have a very good development and meanwhile it is a lot of social responsibility, its development and management control which has become our country market economy an important content of macroeconomic regulation and control. As the market is not steady pace of development, at present our country many construction enterprises in cost management there are still some problems to be solved, the comprehensive cost of the project is higher, the performance review does not reach the designated position, directly affect the enterprise's survival and development. In the future, we plan to optimize the measurement methods to obtain better management approaches.

\section{References}

[1] Zhang X, Hu Y. Online Human Resources Management System for Wood Industry: Adhibition and Manipulation of the Online Human Resources Management System[C]// Internet Technology and Applications, 2010 International Conference on. IEEE, 2010:1 4.

[2] Shi M. The Research of Human Resources Management Information System Based on Tobacco Industry_-Illustrated By the Case of Shenzhen Tobacco[J]. Human Resources Development.

[3] Liu W, Hui-Zi A N, Wang X X, et al. Reflections Build the Coal Enterprise Human Resource Management System[J]. Coal Technology,

2013. 